\title{
Management of Fracture of Posterior Malleolus, Trimalleolar Fracture, Fracture Dislocations, and Syndesmosis Injury of Ankle Joint
}

\author{
${ }^{1}$ Satish R Gawali, ${ }^{2}$ Shashikant B Kukale, ${ }^{3}$ Pramod V Nirvane, ${ }^{4}$ Raman O Toshniwal
}

\begin{abstract}
Background: Malleolar fractures of ankle are usually complex injuries, as they are associated with significant ligament and soft tissue injury-injury to syndesmosis and injury to medial and lateral collateral ligaments. The open reduction and internal fixation is not feasible until recovery of significant soft tissue injury and subsidence of edema. Malleolar fractures are articular fractures and have associated subluxation and dislocation of talus. The aims of treatment are to restore normal anatomy and provide sufficient stability for early movements.

Malleolar fractures more often require open reduction. Our study aimed to know efficacy and outcome of operative management of them.
\end{abstract}

Materials and methods: From January 2013 to March 2015, 35 patients with syndesmotic ankle injury and trimalleolar ankle fractures admitted to the Government Medical College, Latur, India, were operated and followed up prospectively.

Results: Mean age of patients is 35 years (25-60 years). Fracture union was seen radiologically in 3 to 4 months depending on fracture geometry. We achieved good to excellent results of $90 \%$.

Conclusion: We conclude that malleolar fractures encountered in clinical practice need thorough assessment and meticulous surgical intervention, as they are associated with injury to ligament complex, i.e., ligament is a key structure in the stability of ankle mortise. Abduction and external rotation types of injuries are the most common types to be seen. We achieved stable fixation and performed early mobilization of the ankle joint, which limits the complications of mainly ankle stiffness. Each malleolus has got its inherent associated complications and calls for special attention for identifying associated conditions, such as syndesmotic injury, talus dislocation in posterior malleolar fractures, irreducible ankle dislocation with trimalleolar fracture, and entrapped fibula behind tibia with irreducible dislocation.

Keywords: Irreducible fracture dislocations, Malleolar fracture, Syndesmosis injury, Trimalleolar fracture.

How to cite this article: Gawali SR, Kukale SB, Nirvane PV, Toshniwal RO. Management of Fracture of Posterior Malleolus,

\footnotetext{
${ }^{1}$ Associate Professor, ${ }^{2}$ Lecturer, ${ }^{3,4}$ Resident

${ }^{1-4}$ Department of Orthopedics, Government Medical College Latur, Maharashtra, India

Corresponding Author: Satish R Gawali, Associate Professor Department of Orthopedics, Government Medical College Latur, Maharashtra, India, Phone: +919422611201, e-mail: satishgawali61@gmail.com
}

Trimalleolar Fracture, Fracture Dislocations, and Syndesmosis Injury of Ankle Joint. J Foot Ankle Surg (Asia-Pacific) 2017;4(2):90-96.

\section{Source of support: Nil}

Conflict of interest: None

\section{INTRODUCTION}

Malleolar fractures of the ankle are usually complex injuries, as they are associated with significant ligament and soft tissue injury, injury to the syndesmosis ${ }^{1}$ (inferior tibiofibular complex), and injury to medial and lateral collateral ligaments. The open reduction and internal fixation is not feasible until recovery of significant soft tissue injury and subsidence of edema. Malleolar fractures are articular fractures and have associated subluxation and dislocation of talus. The aims of treatment are to restore normal anatomy and provide sufficient stability for early movements.

According to John Roberts, "Ankle is worst injured part of body but least well treated". Malleolar fractures are important as body weight transmission occurs through the ankle and locomotion depends on its stability.

Malleolar fractures require open reduction, more often than any other type of ankle fracture. ${ }^{2}$ Our study aimed to know the efficacy and outcome of operative management of these fractures and follow them prospectively. Clinical and radiological outcomes were studied, and clinical indications and efficacy of procedure reviewed.

After reduction, it is important to check if:

- Articular surface contours are satisfactorily aligned

- Weight bearing alignment of ankle is at right angle to long axis of the leg

- Restoration of normal relationship of ankle mortise has been achieved.

\section{Classification}

Three classifications are used in clinical practice for ankle fractures:

1. Lauge-Hansen classification

2. Dennis-Weber classification

3. AO classification of malleolar fractures

The Lauge-Hansen classification correlates specific fracture patterns with mechanism of injury-the first 
word designates foot's position at the time of injury and second word refers to direction of deforming force.

Most common of all is the supination eversion injury, which leads to the spiral oblique fracture of the distal fibula with fracture of medial malleolus or rupture of deltoid ligament. ${ }^{3}$

Oleany, Ward cautioned against the use of the LaugeHansen classification and recommended treatment based upon clinical judgment of ankle stability.

Whitelaw et al advised anterior drawer and talar tilt test after bony stabilization and surgical repair of ligament disruption.

There is significant interobserver variability and reliability between classification systems of ankle fractures. All the above classification systems are useful in understanding mechanisms of injury and planning treatment, but do not have prognostic significance.

\section{Syndesmotic Injury}

Pronation external rotation and abduction forces the talus to abduct and Ext, rotate out of mortise and causes disruption of syndesmotic ligament. Syndesmosis is assumed to be disrupted if fibula fracture occurs above distal tibiofibular joint. ${ }^{4,5}$

Indications for fixation of syndesmotic injury are controversial in literature studies. In general, syndesmotic screw fixation is not necessary, if lateral malleolus fracture is located within $5 \mathrm{~cm}$ of ankle joint, ${ }^{6}$ and if fracture is anatomically reduced and immobilized for 6 weeks.

If syndesmotic injury extends more than $5 \mathrm{~cm}$ proximal to ankle plafond, the syndesmotic screw fixation is recommended by most authors. ${ }^{7,8}$

Intraoperative cotton test is very useful to test integrity of the syndesmosis. Apply bone hook to distal fibula and try to separate it from tibia and simultaneously apply an opposite force to tibia to prevent movement of tibia. No movement between distal tibia and fibula indicates intact syndesmosis. Lateral displacement for 3 to $4 \mathrm{~mm}$ indicates syndesmosis injury, and syndesmosis fixation is mandatory in these cases.

Various implants are used to fix the syndesmosis. Most commonly used is the 3.5 or 4.5 cortical screw. Two screws are found to provide more biomechanically secure fixations than one screw. Screw placement is done parallel to ankle joint in both cortices of fibula and on one or both cortices of tibia according to bone quality. Screws are routinely removed at 6 to 8 weeks before weight-bearing is allowed (Figs 1 and 2).

\section{Management of Fractures of Posterior Malleolus of Ankle}

Posterior malleolus fracture is often associated with fracture of medial and lateral malleolus. It occurs as a part of rotational injury. The size of posterior malleolus fragment is often variable.

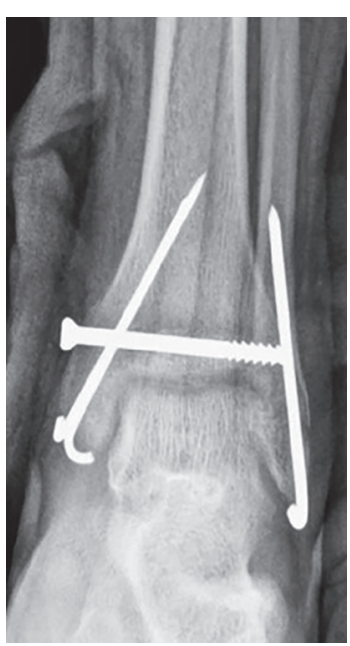

Fig. 1: Case 1 fixation for syndesmotic injury
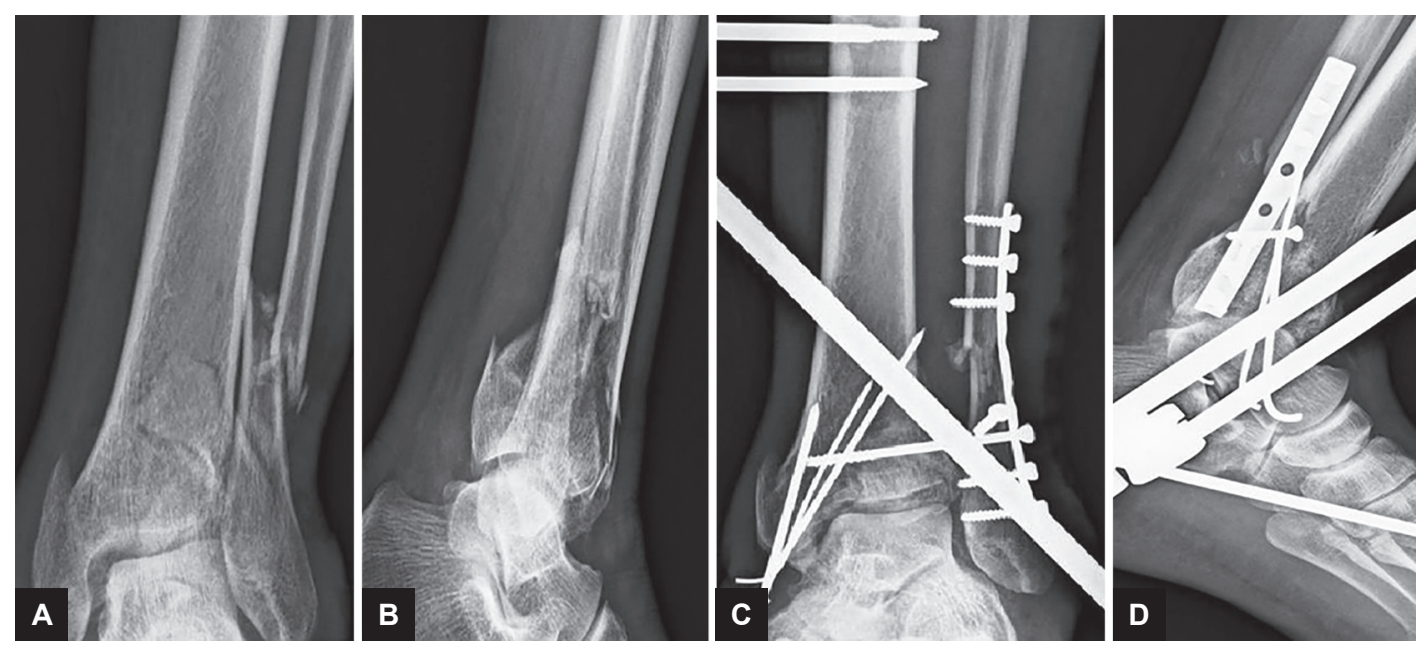

Figs 2A to D: Syndesmosis injury 


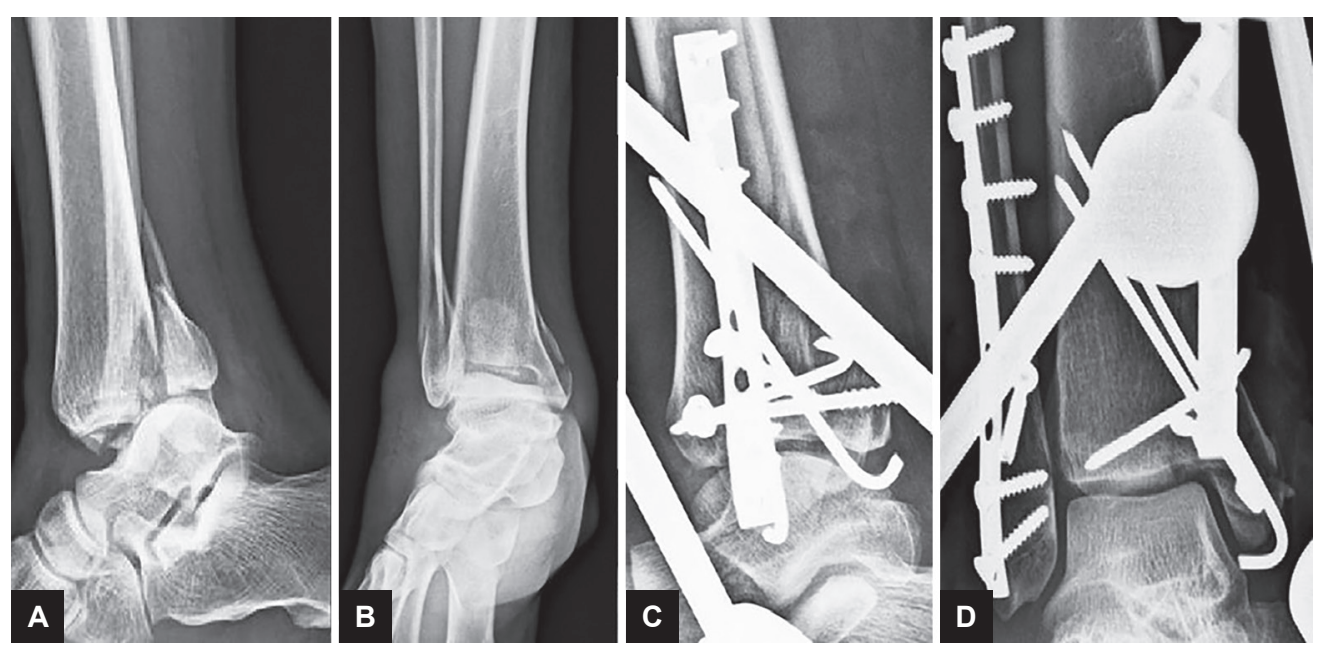

Figs 3A to D: Posterior malleolus fracture fixation

In general, the fragment is small and laterally based and still has attachment in posteroinferior tibiofibular ligament. Large fragments are often associated with posterior ankle subluxation/dislocation as posterior malleolus is a major posterior-stabilizing structure of the ankle.

Posterior malleolus fixation should be undertaken when 25 to $30 \%$ of joint is involved. ${ }^{9}$ In small fragments, when the fibula length is obtained, it sufficiently achieves reduction of posterior malleolar fragment. Most of the small fragment fractures are stable, are reduced conservatively when fibula length is obtained, and yield good results (Fig. 3).

\section{MATERIALS AND METHODS}

The study conducted was on 35 patients (age 25-60 years) with syndesmotic injury and trimalleolar fractures admitted in the Department of Orthopaedics, Government Medical College, Latur, India, between January 2013 and March 2015 (see Table 1).
The purpose of the study is to assess functional outcomes and results of both conservative and operative treatments of syndesmotic injury and trimalleolar fractures. ${ }^{10}$

\section{Exclusion Criteria}

- Compound grade III fracture (Gustilo-Anderson classification)

- Patients who presented after 3 weeks of injury

- Patients with associated talus fracture

- Medically unfit patients

\section{Protocol}

- After admission and stabilization of the patient, radiograph of ankle in anteroposterior, lateral and mortise views were taken and classification of fracture done according to Lauge-Hansen classification (Table 2).

Table 1: Patients characteristics and fracture classification

\begin{tabular}{llllll}
\hline Parameter & Schepers et al & Segal et al & Hancock et al $^{13}$ & Porter et al $^{14}$ & Our study \\
\hline Number of study subjects & 205 & 41 & 62 & 27 & 35 \\
Mean age & 50.7 & 47.3 years & $49( \pm 16.8)$ & $18.1( \pm 5.9)$ & $48( \pm 10.8)$ \\
Gender (M/F) & - & $24 / 17$ & $30 / 32$ & $19 / 08$ & $25 / 10$ \\
Unimalleolar & 117 & 12 & 37 & 08 & 05 \\
Bimalleolar(with syndesmosis) & 57 & 15 & 25 & 14 & 15 \\
Trimalleolar & 31 & 14 & - & - & 15 \\
\hline
\end{tabular}

Table 2: Lauge-Hansen classification

\begin{tabular}{llll}
\hline Parameter & Ma et al & & Xu et al ${ }^{16}$ \\
\hline & Fracture classification & & \\
\hline Supination external rotation (grade II + grade IV) & $50(34+16)$ & 24 & 15 \\
Pronation external rotation (grade II + grade IV) & $21(12+9)$ & 18 & 15 \\
Supination adduction (grade II) & 08 & - & 03 \\
Pronation abduction & 06 & - & 02 \\
\hline Total & 85 & 42 & 35 \\
\hline
\end{tabular}


- Routine lab investigations-hemoglobin, complete blood count, blood sugar testing, liver function tests, kidney function tests, human immunodeficiency virus, surface antigen of the hepatitis B virus, electrocardiogram, and cheat X-ray were done.

- The leg is immobilized with below-knee plaster of paris slab and limb elevation given and oral analgesics started.

- Evaluation of fracture morphology and level and extent of articular involvement were done; evaluation of local skin condition was done. Surgery delayed for presence of blebs, ecchymosis, and gross swelling. ${ }^{17}$

- Surgery was done usually within 12 to 24 hours of injury. In case of blisters, ecchymosis, and swelling, surgery was delayed to 12 to 14 days or when swelling reduces with appearance of wrinkle on skin and after healing of blisters. ${ }^{18}$

- In bad skin conditions, the limb was nursed carefully with $\mathrm{MgSO}_{4}$ dressings, ice application, and limb elevation, and antiedema drugs, such as serratiopeptidase, trypsin, chymotrypsin, bromelain, and rutoside, etc., given. Special attention was given to hemorrhagic blisters, as they indicate underlying skin necrosis. Periodic examination and assessment of skin condition were done.

- Patients with compound fractures were taken for debridement under regional anesthesia within 6 to 8 hours of injury or as early as possible. The intravenous antibiotics were started on admission.

- Routinely, patients were operated with supine position and on radiolucent fracture table. Thorough antiseptic wash, scrubbing with povidone-iodine, and painting and draping done on the operative area. The procedure was done under tourniquet to achieve bloodless operative field and decrease blood loss (see Table 3).

- The lateral malleolus was approached by either closed or open method. In the closed method, we used a square nail that was inserted from the tip of the lateral malleolus. In the open method, it was approached through a posterolateral incision. The incision was made about $5 \mathrm{~cm}$ proximal to tip of lateral malleolus and extends distally along the posterior margin of fibula to the tip of lateral malleolus. Soft tissue and periosteum were separated. One-third tubular plate was contoured to match the fibula or fixed with 3.5 $\mathrm{mm}$ cortical screws. In case of fractures at lower end of fibula, we fixed either with intramedullary $4 \mathrm{~mm}$ cannulated cancellous (CC) screw or two K wires or $3.5 \mathrm{~mm}$ lag screw. ${ }^{21}$

- The medial malleolus was approached with open method, and an incision of $5 \mathrm{~cm}$ from the tip of the medial malleolus between its anterior and posterior borders extending proximally taken. Carefully entrapped periosteum between fracture fragments was elevated. Reduction was achieved with clamp and two parallel $\mathrm{K}$ wires inserted with drill from tip of malleolus. One was anterior and the other was posterior from the tip of medial malleolus to the proximal tibia, transfixing the malleoli of the tibia without entering the joint; if distal fragment size is large enough third $\mathrm{K}$ wire was passed between above two $\mathrm{K}$ wires. In young patients with good bone quality and without comminution, one or two $4 \mathrm{~mm}$ CC screws with or without washer were passed over the guidewire.

- After fixation of medial malleoli, stability of reduction was assessed under image intensifier television control. Special attention is given to look for associated syndesmotic injury by performing Cotton's testdistraction is applied to fibula with bone hook to try to separate it from tibia to which an opposing force has been applied to prevent tibial motion. If no significant motion is noted between distal tibia and fibula, it indicates no syndesmotic injury. If displacement is 3 to $5 \mathrm{~mm}$ or more, one or two syndesmotic screws were passed 1.5 to $3 \mathrm{~cm}$ above ankle plafond and with 25 to 30 anterior inclination from fibula and tibia, engaging two cortices of fibula and one or two cortices of tibia to maintain the reduction of syndesmosis.

- Posterior malleolar fracture was reduced by indirect means without opening the fracture site and guide wire/K wire inserted in anteroposterior direction percutaneously. If posterior malleolus fragment size is small or less than one-third of articular surface, it was managed conservatively without internal fixation. ${ }^{22}$

- A $4.0 \mathrm{~mm}$ CC screw with washer of appropriate size was inserted with small stab incision marked over guide/K-wire and by maintaining reduction by gentle traction over calcaneus.

- The reduction was assessed repeatedly using fluoroscopic and visual control. Rotation of malleolar fragment and integrity of ankle mortise were considered

Table 3: Comparison of operative details with other studies

\begin{tabular}{llll}
\hline Parameter & Noh et al ${ }^{19}$ & Szczęsny and Janowicz & Our study \\
\hline Mean operative time (minutes) & 56.4 & $77.8 \pm 12.0$ & $74.5 \pm 15$ \\
Exposition to fluoroscopy (seconds) & - & $96.1 \pm 103.7$ & $52 \pm 13$ \\
Hospital stay (days) & - & $10.5 \pm 5.5$ & $8 \pm 6.5$ \\
Mean time to bone union (weeks) & 15.8 & - & 16.3 \\
\hline
\end{tabular}



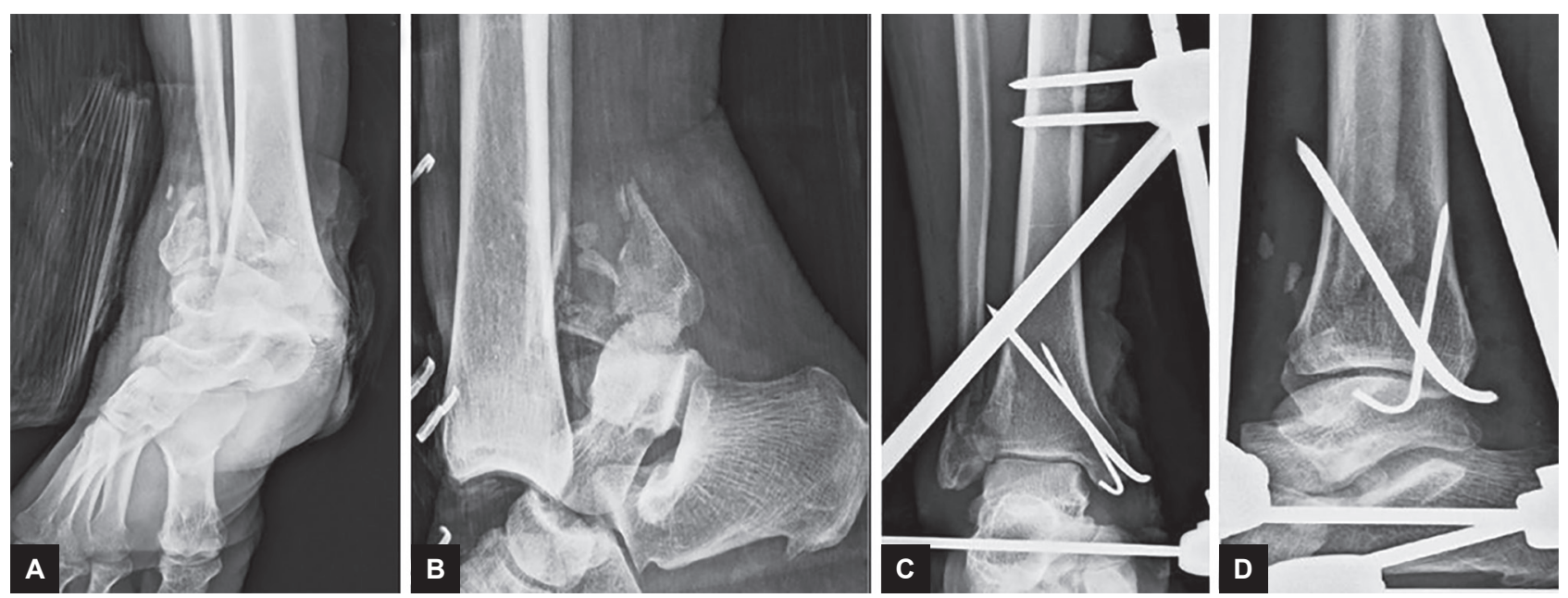

Figs $4 A$ to $D$ : Fracture dislocation

for assessment and delta frame external fixation carried out for reinforcement of fracture stabilization, if trimalleolar fracture is associated with subluxation or dislocation. ${ }^{23}$

- For irreducible fracture subluxation/dislocations:

- Careful assessment was done for entrapment of distal tip of proximal fragment of fibula behind tibia16 (Bosworth's lesion)

- In case of fractured fibula with intact medial malleolus with clear space between talus and medial malleolus, special attention was given for entrapment of torn deltoid ligament or posterior tibial tendons (Fig. 4).

- Postoperatively, limb was elevated, analgesics and anti-inflammatory oral medications were started, IV broad spectrum antibiotics given for 3 days, and oral antibiotics continued until 7 th postoperative day. X-rays were done and assessed for articular configuration and stability of the ex-fixator construct.

- Check dressing on 2nd postoperative day and 7th postoperative day. In cases of external fixator, daily pin tract dressing was done with all aseptic precautions. ${ }^{24}$

- Suture was removed after 12 days on an average or depending on wound healing. Patient was discharged with nonweight-bearing below-knee cast. Range of motion exercises at the knee joint and toes was started on the second day. ${ }^{25}$

- Patient was allowed for nonweight-bearing ambulation using axillary crutches from the 2 nd day. ${ }^{26}$

- Patient was followed up at 4, 8, 12, and 24 weeks for clinical and radiological evaluations, and final results were given at the end of 24 weeks by using Baird and Jackson scoring (see Table 4).

\section{RESULTS AND DISCUSSION}

In our study of 35 patients, patients aged between 25 and 60 years were studied, and the incidence of malleolar fracture
Table 4: Baird and Jackson scoring system

\begin{tabular}{ll}
\hline Pain score & Score \\
\hline No pain & 15 \\
Mild pain with strenuous activity & 12 \\
Mild pain with activities of daily living & 8 \\
Pain with weight-bearing & 4 \\
Pain at rest & 0
\end{tabular}

\section{Stability of ankle}

No clinical instability

Instability with sports activities

Instability with activities of daily living and ability to walk 0 Able to walk

Able to walk desired distances without limp or pain

Able to walk desired distances with mild limp or pain 12

Moderately restricted in ability to walk 8

Able to walk short distances only 4

Unable to walk

Able to run

Able to run desired distances without pain

Able to run desired distances with slight pain

Moderate restriction in ability to run with mild pain

Able to run short distances only

Unable to run

Ability to work

Able to perform usual occupation without restrictions $\quad 10$

Able to perform usual occupation with restrictions in 8 some strenuous activities

Able to perform usual occupation with substantial $\quad 6$ restriction

Partially disabled; selected jobs only 3

Unable to work

Motion of the ankle

Within 10 of uninjured ankle

Within 15 of uninjured ankle

Within 20 of uninjured ankle

$<50$ of uninjured ankle, or dorsiflexion $<5$ 
(Cont'd...)

\begin{tabular}{lc}
\hline Pain score & Score \\
\hline $\begin{array}{l}\text { Radiographic result } \\
\text { Normal anatomical alignment with intact mortise with }\end{array}$ & 25 \\
normal joint space is equivalent to a score of 25 & \\
$\begin{array}{l}\text { Same as above with mild arthritic changes at the joint } \\
\text { is equivalent to a score of } 15\end{array}$ & 15 \\
$\begin{array}{l}\text { Measurable narrowing of the superior joint space, } \\
\text { superior joint space } 2 \text { mm, or talar tilt }>2 \text { mm }\end{array}$ & 10 \\
$\begin{array}{l}\text { Moderate narrowing of the superior joint space, with } \\
\text { superior space between } 2 \text { and } 1 \text { mm }\end{array}$ & 5 \\
$\begin{array}{l}\text { Severe narrowing of the superior joint space, with } \\
\text { superior joint space }<1 \text { mm, widening of the medial } \\
\text { clear space, severe reactive changes(sclerotic } \\
\text { subchondral bone and osteophyte formation) }\end{array}$ & 0 \\
\hline
\end{tabular}

Table 5: Functional outcome as per Baird and Jackson scoring

\begin{tabular}{lllll}
\hline & \multicolumn{4}{c}{$\begin{array}{c}\text { Functional outcome according to Baird } \\
\text { and Jackson scoring (percentage) }\end{array}$} \\
\cline { 2 - 5 } Study & Excellent & Good & Fair & Poor \\
\hline Ma et al ${ }^{16}$ & 53.00 & 23.00 & 6.00 & 3.00 \\
Xu et al $^{17}$ & 42.61 & 38.09 & 9.52 & 4.76 \\
Our study & 51.3 & 29.7 & 14.2 & 4.8 \\
\hline
\end{tabular}

was found to be high in the age group of 30 to 50 years. Meticulous surgical procedures and periodic follow-ups of posterior malleolus injury are key in its management. ${ }^{27}$

Out of 35 patients, 25 fractures were found in men and 10 fractures were in females. Trimalleolar fracture was seen in 15 patients, 15 patients had syndesmotic injury ankle fracture, whereas 5 patients had isolated posterior malleolus fracture. The union occurred in a mean period of 12 to 16 weeks (see Table 5).

\section{CONCLUSION}

We conclude that malleolar fractures encountered in clinical practice need thorough assessment and meticulous surgical intervention, as they are associated with injury to ligament complex, i.e., ligament is a key structure in the stability of ankle mortise. Abduction and external rotation types of injuries are the most common types to be seen. We achieved stable fixation and performed early mobilization of the ankle joint, which limits the complications of mainly ankle stiffness. Each malleoli has got its inherent associated complications and calls for special attention for identifying associated conditions, such as syndesmotic injury, talus dislocation in posterior malleolar fractures, irreducible ankle dislocation with trimalleolar fracture, and entrapped fibula behind tibia with irreducible dislocation. ${ }^{28}$

\section{REFERENCES}

1. Shelton Marvin, L. Complication of fractures and dislocation of the ankle. In: EPPS, Charles H, editors. Complications in orthopaedic surgery. Chap. 23. 3rd ed. Vol. 1. Philadelphia (PA): J.B. Lippincott Company; 1994. p. 595-648.

2. Beris AE, Kabbani KT, Xenakis TA, Mitsionis G, Soucacos PK, Soucacos PN. Surgical treatment of malleolar fractures-a review of 144 patients. Clin Orthop Relat Res 1997 Aug;341:90-98.

3. Weber, MJ. Ankle fractures and dislocations. In: Chapman MW, Madison M, editors. Operative orthopaedics. Chap. 50. 2nd ed. Vol. 3. Philadelphia (PA): J.B. Lippincott Company; 1993. p. 731-748.

4. Wilson, FC. Fractures and dislocations of the ankle. In: Rockwood CA, Green DP, editors. Fractures in adults. Chap. 18. 2nd ed. Vol. 2. Philadelphia (PA): J.B. Lippincott Company; 1991. p. 1983-2040.

5. Desouza, LJ. Fractures and dislocations about the ankle. In: Gustilo RB, Kyle RF, Templeman D, editors. Fractures and dislocations. Chap. 30. Vol. 2. St. Louis (MO): Mosby Year book Inc.; 1993. p. 997-1043.

6. Yablon IG, Heller FG, Shouse L. The key role of the lateral malleolus in displaced fractures of the ankle. J Bone Joint Surg 1977 Mar;59(2):169-173.

7. Gutmann, G. Ankle fractures. In: Scurran BL, editor. Foot and ankle trauma. Chap. 28. New York: Churchill Livingstone; 1989. p. 579-638.

8. Griend, RAV.; Savoie, FH.; Hughes, JL. Fractures of the ankle. In: Rockwood CA, Green DP, Bucholz RW, editors. Rockwood and Green's fractures in adults. Chap. 23. 3rd ed. Vol. 2. Philadelphia (PA): J.B. Lippincott Company; 1991. p. 1983-2040.

9. Beauchamp CG, Clay NR, Thexton PW. Displaced ankle fractures in patients over 50 years of age. J Bone Joint Surg Br 1983 May;65(3):329-332.

10. Pettrone FA, Gail M, Pee D. Fitzpatrick T, Van Herpe LB. Quantitative criteria for prediction of the results after displaced fracture of the ankle. J Bone Joint Surg 1983 Jun;65(5):667-677.

11. Schepers T, De Vries MR, Van Lieshout EM, Van der Elst M. The timing of ankle fracture surgery and the effect on infectious complications; a case series and systematic review of the literature. Int Orthop 2013 Mar;37(3):489-494.

12. Segal G, Elbaz A, Parsi A, Heller Z, Palmanovich E, Nyska M, Feldbrin Z, Kish B. Clinical outcomes following ankle fracture: a cross-sectional observational study. J Foot Ankle Res 2014 Nov;7(1):50.

13. Hancock MJ, Herbert RD, Stewart M. Prediction of outcome after ankle fracture. J Orthop Sports Phys Ther 2005 Dec;35(12):786-792.

14. Porter DA, May BD, Berney T. Functional outcome after operative treatment for ankle fractures in young athletes: a retrospective case series. Foot Ankle Int 2008 Sep;29(9): 887-894.

15. Ma J, Li Y, Wang Z. Surgical techniques of open reduction and internal fixation for ankle fracture. Zhongguo Xiu Fu Chong Jian Wai Ke Za Zhi 2008 Apr;22(4):456-458.

16. Xu YQ, Zhan BL, He FX, Wei HD. Surgical treatment of pronation and supination external rotation trimalleolar fractures. Zhongguo Gu Shang 2008 Apr;21(4):300-301.

17. Lindsjö U. Operative treatment of ankle fracture-dislocations. Clin Orthop Relat Res 1985 Oct;199:28-38.

18. Johnson EE, Davlin LB. Open ankle fractures. The indications for immediate open reduction and internal fixation. Clin Orthop Relat Res 1993 Jul;292:118-127. 
19. Noh JH, Roh YH, Yang BG, Kim SW, Lee JS, Oh MK. Outcomes of operative treatment of unstable ankle fractures: a comparison of metallic and biodegradable implants. J Bone Joint Surg Am, 2012 Nov 94(22):e166.

20. Szczęsny G, Janowicz J. Minimally invasive osteosynthesis of ankle fractures. Pol Orthop Traumatol 2012 Nov;77:145-150.

21. Limbird RS, Aaron RK. Laterally comminuted fracturedislocation of the ankle. J Bone Joint Surg Am 1987 Jul;69(6): 881-885.

22. Bauer M, Bergström B, Hemborg A, Sandegård J. Malleolar fractures: nonoperative versus operative treatment. Clin Orthop Relat Res 1985 Oct;199:17-27.

23. Segal D, Wasilewski S. Total dislocation of the talus. J Bone Joint Surg Am 1980 Dec;62(8):1370-1372.

24. Carragee EJ, Csongradi JJ, Bleck EE. Early complications in the operative treatment of ankle fractures. Influence of delay before operation. J Bone Joint Surg (Br) 1991 Jan;73(1):79-82.
25. Hedström M, Ahl T, Dalén N. Early postoperative ankle exercise: a study of postoperative lateral malleolar fractures. Clin Orthop Relat Res 1994 Mar;300:193-196.

26. Dogras AS, Ranga A. A prospective randomised control study comparing early mobilisation versus immobilization of surgically treated ankle fractures (abstract). J Bone Joint Surg Br 1997 Sep;79(Suppl 3):367-368.

27. Papachristou G, Levidiotis C, Temertzoglou A, Efstathopoulos N. Early weight bearing following ORIF of posterior malleolar fractures of the ankle joint. J Bone Joint Surg Br 1999;81-B(Suppl II):181.

28. Geissler, WB.; Tsao, AK.; Hughes, JL. Fractures and injuries of ankle. In: Rockwood CA, Green DP, bucholz RW, Heckman JD, editors. Rockwood and Green's fractures in adults. Chap. 31. 4th ed. Vol. 2. Philadelphia (PA): Lippincott Raven; 1996. p. 2201-2266. 